\title{
Laudation for Dr. Eric Christopher Grunsky, William Christian Krumbein Medal 2012
}

Published online: 12 October 2012

(C) International Association for Mathematical Geosciences 2012

Dr. Grunsky is the worthy recipient of the 2012 William Christian Krumbein Medal because of his long and continuous service to the IAMG community as a scientist in the fields of mathematics and statistics in the earth sciences, as a supporter of the Association, and for his service to the profession.

Eric's service and recognition within the IAMG and elsewhere have been awarded in the past. He received the Felix Chayes Prize for Excellence in Research in Statistical Petrology in 2005 and was honored as a Visiting Research Fellow, Edith Cowan University, Western Australia in 2011. He has also been appointed as an adjunct professor at two universities in Ontario, Canada.

Eric's career has been long and varied during which he developed expertise that has resulted in significant contributions to the earth sciences. During his undergraduate years at the University of Toronto (1969-1973), he developed a keen interest in the quantitative aspects of geosciences through the use of computers. His interest was encouraged by Professor Gordon Smith who mentored Eric on the use of computers to solve a variety of quantitative problems. His M.Sc. thesis, with Professors Fried Schwerdtner, Pierre Robin, and Dick Bailey, at the University of Toronto, was one of the earlier studies in three-dimensional analysis of reconstructed tectonites by means of the integration of digital serial sections.

After completing his M.Sc. degree (1975-1978), Eric was hired by the Ontario Geological Survey (OGS). His duties included not only detailed and regional geological field mapping, but also introducing the use of computers into the organization. Eric's leadership in this area enabled the adoption of computer technology throughout the OGS. He led an internal review on the management and access of geoscience data, which contributed to a restructuring of the OGS Geoscience Data Centre. In the mid-1980s, his research started to focus on the use of geochemistry and statistics for evaluating patterns related to primary compositional variation in volcanic rocks, and also the recognition of alteration and base- and precious-metal mineralization. At the same time, he became aware of the work by John Aitchison: the issue of closure and 
its pertinence in examining whole rock geochemistry. His studies, presentations, and publications on the statistical evaluation of geochemical data and its value in mineral exploration were quickly recognized by the mineral exploration community at both the national and international levels. As well, his interest in spatial analysis and a meeting with Graeme Bonham-Carter and myself resulted with his enrolment in a $\mathrm{Ph} . \mathrm{D}$. program at the University of Ottawa under my supervision. Eric was commuting from Toronto to Ottawa where we enjoyed his biweekly or monthly visits.

Upon completion of his Ph.D. (1985-1988), Eric was offered employment by the Division of Exploration and Mining Commonwealth Scientific and Industrial Research Organization (CSIRO), Australia. While at CSIRO, he studied the geochemistry of laterite and other weathered materials using statistical methods and introduced the use of multivariate statistical methods to the Australian mineral exploration community. He was invited to give several short courses on the use of numerical and statistical methods to the mineral exploration industry and graduate level university courses. It was during this time that Eric had the opportunity to meet Vera Pawlowsky at a conference on the statistical prediction of mineral resources in Wuhan, China, where they discovered a mutual interest in the statistics of compositional data.

In 1991, Eric was offered the opportunity to work on a mineral resource assessment project at the British Columbia Geological Survey, Canada. This project allowed him to realign his knowledge of statistics and his background in regional geological studies for the creation of grade-tonnage models that were uniquely defined for British Columbia mineral deposits as well as the adaptation of the USGS Mark 3 mineral resource estimation simulator for estimating resource potential in the province.

Eric's background in geoscience information management from his time at the OGS led to an opportunity to develop an information management strategy for the Alberta Geological Survey (AGS) from 1998 to 2002. His leadership in the knowledge of both managing and delivery of digital geoscience information allowed him to work at the national level with provincial, territorial, and national agencies in developing an integrated national geoscience delivery structure.

During his time at the AGS, he became involved in the study of multibeam radar satellite imagery as a tool for terrain mapping. Eric designed and managed one of the largest RADARSAT-1 image acquisition campaigns for a provincial agency ever implemented by the Canadian Space Agency, one that resulted in more than 280 images of varying incidence angles and look directions. Using his knowledge of multivariate statistical methods, Eric demonstrated that unique features of landforms could be effectively identified and mapped at the regional scale. Eric's innovative approach to evaluating RADARSAT-1 satellite imagery was recognized by the Canadian Space Agency through several invitations to present his work at national meetings and agency operational reviews.

In 2002, Eric accepted a position at the Geological Survey of Canada in Ottawa as an information management specialist for the Mineral Resources Division, a position he received in large part for his knowledge of quantitative methods for evaluating geochemical data. Eric quickly became involved with a number of projects that enabled him to study and describe geochemical/geological processes from a range of geochemical datasets. As well, his previous work on three-dimensional spatial analysis was revived for specialized geochemical studies in the Noranda mining camp 


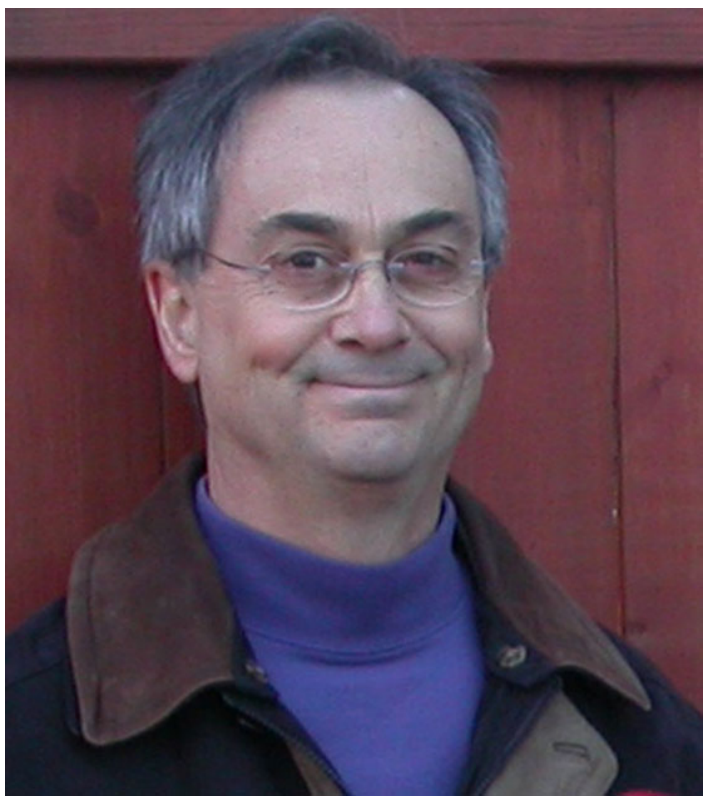

in Quebec. During the next 9 years, Eric became involved in geochemical studies of kimberlites, as well as lake, stream, and soil sediments for a wide range of projects within the GSC. Additionally, he became involved in the statistical analysis studies of soil and stream sediment geochemistry with the United States Geological Survey (USGS) and Geoscience Australia (GA). Eric also participated in two of the compositional data analysis workshops that were held in Girona and Saint Felieu de Guixols, Spain, by Vera Pawlowsky's research group.

Larry Drew at the US Geological Survey in Reston, Virginia, has had the good fortune to work with Eric since 2005, during which time they have successfully solved several problematic issues in the interpretation of the geochemistry of soils and stream sediments. Eric's background knowledge and enthusiasm to carry out research into new areas has certainly made a significant contribution to the field through their work.

Eric's use of statistical methods for integrating satellite imagery formed the basis for a new paradigm of surficial materials mapping across Canada's North. During his time at the GSC, he worked with surficial mapping geologists and remote sensing geologists to develop a methodology for surficial materials mapping, based on the statistical integration and classification of satellite imagery derived from radar and optical sensors. This approach has defined a new large scale mapping process that has been implemented by the GSC as part of its northern mapping strategy.

Throughout his professional career, Eric has documented his research findings through publications and presentations. He has published 39 articles in peer-reviewed journals, 5 review articles, 80 government reports, maps and open file reports, 11 contributions to books, 70 conference proceedings and public reports, 23 solicited consultations by outside agencies and 149 invited conference/presentations/lectures. 
Eric has been invited on international scientific committees for the IAMG and the International Association of Applied Geochemists.

He is currently an Adjunct Professor at the University of Waterloo in the Departments of Earth Sciences and Biology and as an adjunct professor in the Department of Earth Sciences at Laurentian University where he has lectured on the use of statistics in the interpretation of geochemical data and mentored and supervised graduate students in the use of statistics for evaluating geoscience data.

Dr. Grunsky has been a member of the IAMG since 1985. He has served as Editor-in-Chief, Computers \& Geosciences from 2006 to 2011 after being an Associate Editor from 1996 to 2006. Currently, he serves on the Board of Mathematical Geosciences. He also was on the Editorial board of Geochemistry: Exploration, Environment, Analysis (2001-present), and Natural Resources Research (1999-2006). Dr. Grunsky's commitment to the IAMG is also demonstrated through his service as elected Councillor (1992-1996). He initiated the development of the IAMG ftp and web sites and was the IAMG website manager from 1995 to 2006. Eric is married to Jean Hubay. With their two children, Kurt and Anna, they live in Ottawa, Ontario.

Dr. Grunsky's current contributions to the quantitative aspects of earth science are built on his experience and knowledge from the past. As well, however, he is keen to learn and discover new ways of looking at data and developing/enhancing statistical methodologies. Dr. Grunsky is the consummate scientist-he never stops learning and achieving!

Frits Agterberg

Geological Survey of Canada

615 Booth St.

Ottawa, Ontario, K1A 0E8

Canada

e-mail: Frits.Agterberg@NRCan-RNCan.gc.ca 